\title{
PENDIDIKAN ISLAM DI MESIR, INDIA, DAN PAKISTAN
}

\author{
Yesi Arikarani
}

STAI Bumi Silampari Lubuklinggau

yesi.arikarani@staibsllg.ac.id

\begin{tabular}{|c|c|}
\hline \multicolumn{2}{|r|}{ Abstrak } \\
\hline $\begin{array}{l}\text { Article History } \\
\text { Received : 26-01-2019 } \\
\text { Revised : 28-01-2019 } \\
\text { Accepted : 03-02-2019 } \\
\text { Keywords : } \\
\text { Education in Islam, } \\
\text { Egypt, India } \\
\text { and Pakistan }\end{array}$ & $\begin{array}{l}\text { Islamic education enters along with } \\
\text { the early history of Islam in the form } \\
\text { of civilization such as the Egyptian } \\
\text { culture of the pyramids, sphinxes, } \\
\text { obelisks, and hieroglyphics. the } \\
\text { figures who have contributed to the } \\
\text { field of education are Muhammad } \\
\text { Abduh, Sayyid Ahmad Khan, and } \\
\text { Muhammad Ali Jinnah. The } \\
\text { application of education between } \\
\text { Egypt, India, and Pakistan is almost } \\
\text { the same, namely making } \\
\text { compulsory education for their } \\
\text { citizens. The existence of public and } \\
\text { religious/Madrasah educational } \\
\text { institutions as well as public and } \\
\text { religious high schools / universities. } \\
\text { Different curriculum. Application of } \\
\text { the learning of the Qur'an and } \\
\text { Hadith. Integrate between general } \\
\text { science and religious science. } \\
\text { professional teaching staff. Every } \\
\text { country has a different education } \\
\text { system influenced by sociology of } \\
\text { society, the history of the } \\
\text { establishment of a country, the } \\
\text { needs of a country in accordance } \\
\text { with the demands of the era and an } \\
\text { increasingly globalized world. }\end{array}$ \\
\hline
\end{tabular}

\section{Pendahuluan}

Pendidikan telah lama dikenal sejak awal Islam. Pada masa awal, pendidikan idektik dengan upaya da'wah Islamiyah, karena itu 
pendidikan berkembang sejalan dengan perkembangan agama itu sendiri. Rahman dalam (Sanaky 1997: 2) menyatakan kedatangan Islam membawa untuk pertama kalinya suatu instrumen pendidikan tertentu yang berbudayakan agama, yaitu al-Qur'an dan ajaran-ajaran Nabi. Pada masa awal perkembangan Islam, pendidikan formal belum terselenggara sistematis. "lembaga pendidikan tertua dalam Islam walaupun tidak disebut majelis taklim namun pengajian Nabi Muhammad SAW yang berlangsung secara sembunyi-sembunyi di rumah sahabat Arkam bin Abil Arqam RA. Di zaman Makkah, dapat dianggap majelis taklim menurut pengertian sekarang. Setelah terangterangan pengajian seperti itu segera berkembang di tempat-tempat lainnya yang diselenggarakan secara terbuka. (Departemen Agama dalam

Sejarah pendidikan di Mesir, khususnya Al-Azhar memiliki keterkaitan dengan dinamika keberagamaan Islam di tanah air dapat di saksikan dari kiprah para alumninya yang telah begitu banyak mengisi dan mengembangkan keilmuan yang mencakup semua aspek kehidupan sosial, politik, budaya dan keagamaan. Peran mereka tersebar mulai dari penceramah, akademisi, pengusaha, budayawan, penegak hukum dan politikus. Berbicara soal peran alumni Al-Azhar Mesir di Indonesia, hal tersebut tidak terlepas dari sejarah perkembangan Islam di tanah air. Mengingat, Al-Azhar merupakan institusi pendidikan yang telah banyak melahirkan tokoh-tokoh pembaharu di dunia, sebagaimana telah diuraikan di atas, juga telah melahirkan para tokoh yang sama di Indonesia. Hampir semua tokoh Islam modern pernah belajar dengan para guru yang berijazah AlAzhar.

Hubungan antara Indonesia dan Mesir telah berlangsung cukup lama, yaitu diperkirakan sejak saat orang Mesir menggunakan kapur yang berasal dari Barus di Pulau Sumatera sebagai salah satu bahan pengawet mumi di Mesir. Selanjutnya dalam perjalanan sejarah, Indonesia dan Mesir memiliki banyak persinggungan sejarah yang saling menguatkan satu sama lain seperti perkembangan Islam dan sejarah modernisasi negara dan pendidikan. Kedua, pendidikan di Mesir, khususnya di Universitas Al Azhar mengajarkan paham keagamaan Islam yang sesuai dengan budaya Indonesia yang multikultur dan beragam.(Murtadlo, 2018: 305) 
Begitu juga pendidikan Islam di India yang kita kenal kerajaan munghal di India bahwa pendidikan Islam yang berkembang pada zaman dinasti Mughol masuknya Islam ke India selain menggunakan media politik, dakwah dan diplomasi, juga menggunakan media pendidikan. Kerajaan mughol berdiri seperempat abad sesudah berdirinya kerajaan safawi. Keadaan pendidikan banyak terkonsentrasi pada pewarisan dan pemeliharaan pemikiran keagamaan yang telah dihasilkan para ulama zaman klasik, tanpa memberanikan diri untuk melakukan pembaharuan ataupun menghasilkan karya pemikiran yang baru atau berbeda dengan pemikiran yang ada sebelumnya. Para ulama yang lahir pada zaman Moughol ini ini hanya menyimpan, menguasai, dan meneruskan ajaran yang telah terususun oleh para ulama sebelumnya. Dengan membangun madrasah-madrasah dan melahirkan karya inovatif dalam ilmu pengetahuan umum.

Negara Pakistan Sekarang, terjadi akibat pemisahan dengan pemerintahan India pada 14 Agustus 1947, sejak awal abad ke-19, Inggris mulai mendominasiwilayah tersebut. Secara integral fenomena tersebut berkait erat dengan perjuangan kaum Muslimin India kemudian sebagai manifestasi dari kegiatan politik tersebut umat Islam menentukan sendiri nasib dalam pembentukan wilayah merdeka. Dan Pakistan adalah satu-satunya negara yang unik diantara negara-negara Muslim yang lahir pada abad ke-20 dimana dalam landasan dasarnya didirikan atas nama Islam. (Surawardi, 2012:24)

Dengan demikian berbicara mengenai pendidikan islam di mesir, india dan Pakistan. Mesir yang terkenal dengan sebutan ardhul anbiya (negeri para nabi) memang telah menjadi kiblat keilmuan keislaman dunia. Selain mempunyai se- gudang peradaban, negeri seribu menara ini juga merupakan gudang segala ilmu. Negara ini seakan memiliki magnet tersendiri. Terbukti, Mesir telah memikat jutaan hati para pelajar dari berbagai penjuru dunia, termasuk dari Indonesia, untuk menimba ilmu di sana. peran Al- Azhar sebagai pusat pendidikan tertua. filosofis pendidikan Mesir bertujuan mendidik akal dan jiwa serta mengembangkannya hingga batas-batas yang memungkinkan peserta didik mencapai kebahagiaan hidup di dunia dan di akhirat sehingga terwujud pribadi Muslim.(Yunitasari, 2017:127) 
India berawal dari sejarah masuknya Islam, seorang tokoh yang berpengaruh pada masa itu, dan membawa sebuah pembaharuan di bidang pendidikan. Untuk pendidikan Islam di india oleh Sayyid Ahmad Khan adalah salah seorang tokoh pembaharuan pemikiran Islam pada Abad ke-18 di India. Dia mempunyai kreatifitas intelektual yang tinggi, luas dan ikut memperkaya khazanah intelektual Islam.Pemikiran Sayyid Ahmad Khan dalam aspek pendidikan muncul dalam bentuk mengawinkan sistem pendidikan modern dengan ajaran Islam, dan pemikiran Sayyid Ahmad Khan dalam aspek theologi relevan dengan nash-nash Al-Quran dan Hadits serta tuntutan zaman. (Akmal 2015:16) karena untuk memajukan umat Islam satu-satunya jalan adalah melalui pendidikan. Melalui pendidikan akan lahirlah para intelektual Islam.

Akar sejarah terbentuknya pemerintahan pakistan adalah adanya semangat keagamaan yang kuat atas pengaruh mayoritas Hindu yang terdapat di India sehingga akhirnya terlahirlah negara Pakistan yang mengatasnamakan negara Islam Pakistan dan secara resmi disebutkan pada Undang-Undang Pemerintahan Pakis- tan. Lainya halnya dengan di Indonesia ter bentuknya Negara RI adalah adanya semangat nasionalis dalam memperjuangkan ke- merdekaan dari penjajah. Semangat nasion- alis tersebut tanpa membedabedakan suku agama dan bahasa sehingga Indonesia bukan negara Muslim meskipun termasuk negara mayoritas muslim terbesar di dunia. Kebijakan pendidikan antara Pakistan dan Indonesia hampir sama yakni menjadi- kan pendidikan wajib belajar bagi warga negaranya. Hanya saja Pakistan wajib bela- jarnya hingga tingkat SLTA sementara di Indonesia hanya sampai tingkat SLTP. Sementara lembaga pendidikan yang terdapat di Pakistan dan Indonesia juga hampir sama yakni adanya lembaga pendidikan Umum dan Agama /Madrasah serta sekolah tinggi/universitas baik umum dan keagamaan. (Surawardi 2012:51)

Berdasarkan dari beberapa literatur disebutkan mengenai sejarah dan pendidikan Islam di mesir, india dan Pakistan dapat dikaji lebih mendalam menjelskan pendidikan Islam yang ada di mesir, sistem pendidikannya dan kurikulumnya. Begitu juga dengan india dan Pakistan. 


\section{Metode Penelitian}

Metode yang digunakan dalam tulisan ini bersifat deskriptif kualitatif yang bertujuan untuk mendeskripsikan tentang sejarah Islam di bidang pendidikan. Dengan cara mencatat, menganalisis dan menginterpretasikannya bertujuan untuk memperoleh informasi yang dibutuhkan. jenis penelitian adalah studi literatur merupakan penelitian dengan mengumpulkan data yang diperlukan dari literaturliteratur yang berkaitan. Buku-buku, jurnal-jurnal yang berkaitan dengan pendidikan Islam di mesir, india dan pakistan.

\section{Pembahasan}

\section{Pendidikan di Mesir}

Pendidikan islam formal bermula dari sejarah berdirinya masjid pertama. Dari masjid 'Amru Bin 'Ash Dan Masjid Ibn Thulon, pendidikan di mesir berpindah ke Masjid al-azhar. (Kedutaan Besar Republik Indonesia, 1983: 31) Sementara itu, tumbuh tradisi belajar membaca dan menghafal al-qur'an yang diselenggarakan di luar masjid oleh lembaga pendidikan yang disebut kuttab. Pendidikan kuttab mensupply pendidikan masjid dengan anak didik yang tahu baca tulis serta hafal al-qur'an. Disamping masjid, juga berkembang pendidikan madrasah yang kadang-kadang merupakan partner pendidikan masjid atau kelanjutannya. Dalam konteks ini belum dikenal pemisahan apa yang disebut pendidikan agama dan pendidikan umum. Kemudian pada masa pemerintahan muhammad ali telah menjadi permulaan masa transisi dari pendidikan tradisional kepada pendidikan modern. Adapun madrasah yang di bangun di mesir pada masa al-ayyubi yaitu: al-quthbiyyah, manazil 'az, madrasah fayyum, al fadhiliyah, al-azkasyiyah, as-saifiyah, dan sebagainya. (Kedutaan Besar Republik Indonesia, 1983: 36)

Sekolah modern pada masa muhammad ali pasya merupakan permulaan penyisihan sebenarnya antara institusi politik dan keagamaan di mesir modern. Muhammad ali pasya mendirikan sekolah akonting pada tahun 1826, sekolah sipil pada tahun 1834. Ia juga membuka sekolah industri dan sekolah irigasi pada tahun 1831, dan tiga tahun kemudian ia membuka sekolah pertanian. Muhammad ali membangun berbagai macam sekolah teknik bertujuan untuk melatih tenaga kerja. Dari masa pemerintahan muhammad ali pasya ini dalam sistem pendidikannya banyak mengalami kesulitankesulitan. Dapat kita ketahui bahwa pada masa muhammad ali ini 
mulai berjalan dua sistem pendidikan yang paralel tetapi terpisah, yaitu pendidikan tradisional dan pendidikan modern sekular. Akibatnya, intelektual hasil pendidikan ini juga terbagi dua: alumni sekolah agama dan alumni sekolah modern.

Kemudian selain dari membuka sekolah moderen, pembaharuan muhammad ali diantaranya Mengirim Mahasiswa belajar keluar negeri dan Menterjemahkan buku-buku bahasa asing kedalam bahasa Arab. Dengan demikian tentu, perkenalan dengan pemikiran baru dari barat tidak hanya terbatas dilingkungan mereka yang berpendidikan barat saja. Pemikiran dan ilmu baru dapat pula diserap oleh mereka yang belum pernah keluar negeri dan tidak tahu bahasa asing. (Harun Nasution, 1975: 38)

Cikal bakal munculnya pemikiran modern diawali dengan pemikiran salah seorang tokoh pembaharu dari mesir yakni Muhammad Abduh. Target pembaharuan Muhammad Abduh:

1. Purifikasi. Pemurnian ajaran Islam mendapat perhatian serius dari Muhammad Abduh berkaitan dengan munculnya bid'ah dan khurafatyang masuk dalam kehidupan beragama umat Islam

2. Reformasi. Muhammad Abduh, dalam mereformasi pendidikan tinggi Islam terkonsentrasi pada universitas almamaternya, alAzhar. Ia menyatakan bahwa kewajiban belajar itu tidak hanya mempelajari buku-buku klasik berbahasa Arab yang berisi dogma ilmu agama untuk membela Islam. Akan tetapi, kewajiban belajar juga terletak pada mempelajari sains-sains modern, serta sejarah dan agama Eropa, agar diketahui sebabsebab kemajuan yang telah mereka capai.

3. Pembelaan Islam. Muhammad Abduh, melalui Risalah Tauhidnya tetap mempertahankan jati diri Islam. Usahanya untuk menghilangkan unsur- unsur asing merupakan bukti bahwa ia tetap yakin dengan kemandirian Islam. Abduh, terlihat tidak pernah menaruh perhatian pada paham-paham ateis atau anti agama yang marak di Eropa. Ia lebih tertarik untuk memperhatikan serangan-serangan terhadap Islam dari sudut keilmuan.

4. Reformulasi. Agenda ini dilaksanakan Abduh dengan membuka kembali pintu ijtihad. Karena menurutnya, kemunduran umat Islam disebabkan dua faktor: eksternal dan internal, yakni kejumudan umat Islam sendiri. Abduh dengan refomulasinya menegaskan bahwa Islam telah membangkitkan akal pikiran 
manusia dari tidur panjangnya, sebenarnya manusia tercipta dalam keadaan tidak terkekang, termasuk dalam hal berpikir.(Sukino 2016:30-31)

pemikiran Muhammad Abduh dalam pembaruan pendidikan yakni dalam bukunya Abdul Sani:

a. Menentang dan menghilangkan dualisme dalam pendidikan.

Gagasan Abduh yang paling mendasar dalam system pendidikan adalah bahwa ia sangat menentang system dualisme. Menurutnya, dalam sekolah-sekolah umum harus diajarkan agama, sedangkan dalma sekolah-sekolah agama harus di ajarkan ilmu pengetahuan modern. Abdul Mu'in Hamadah mengemukakan bahwa salah satu agenda pembaharuan pendidikan yang dilakukan Muhammad Abduh adalah perlunya perluasan dalam kajian pengetahuan. (Abdul Sani, 1998:54)

b. Merumuskan tujuan lembaga pendidikan sesuai dengan struktur satuan pendidikan.

Dalam merumuskan tujuan pendidikan, Muhammad Abduh selalu menghubungkan antara tujuan yang satu dengan yang lain, baik tujuan akhir maupun tujuan institusional.

c. Menyusun kurikulum

Muhammad Abdul merumuskan kurikulum berdasarkan tingkat pendidikan, yaitu tingkat pendidikan dasar dan menengah dan pendidikan tinggi. Pengorganisasian kurikulum didasarkan pada pembagian manusia sesuai dengan lapangan pekerjaan yang akan mereka geluti. Berdasarkan lapangan kerja tersebut ia mencoba merencanakan kurikulum pendidikan pada setiap tingkat pendidikan tertentu agar setelah anak didik selesai mengikuti jenjang pendidikan tersebut ia dapat melaksanakan tugasnya sesuai dengan tuntunan Agama Islam dan perkembangan jaman. (Ramayulis, 2012: 189).

d. Pengembangan keterampilan dan pengetahuan guru. Pengembangan keterampilan dan pengetahuan guru yang dilakukan di Mesir lebih mengarah pada pemenuhan standar kompetensi yang tidak hanya untuk memenuhi standar nasional, tetapi juga untuk peningkatan kemampuan standar internasional. Arah kebijakan ini memiliki nilai strategis dalam penyiapan sumber daya manusia (SDM) guru yang 
mampu mengawal pendidikan yang berkualitas di masa mendatang. Peningkatan kompetensi guru seperti ini sesungguhnya sangat relevan dengan kebijakan pendidikan di Indonesia yang kini tengah dengan giat mewujudkan pendidikan yang bermutu, yang tidak saja dapat memenuhi standard Nasional Pendidikan (SNP) tetapi juga untuk meningkatkan kemampuan peserta didik dalam menguasai standard internasional.(Yunitasari 2017:124-25)

\section{Sistem Pendidikan di Mesir}

Sistem pendidikan mesir mempunyai dua struktur parallel : struktur sekuler dan struktur keagamaan Al-Azhar. Struktur sekuler diatur oleh Kementrian Pendidikan. Dalam penyeleksian tenaga pengajar, sebagai lembaga internasional yang bergerak dalam bidang pendidikan, UNESCO Mesir mengembangkan suatu sistem pelatihan guru untuk mendukung tercapainya sumber daya manusia Mesir yang handal. Training ini diselenggarakan melalui kerjasama dengan perusahan-perusahaan besar yang berperan dalam melakukan sertifikasi keahlian guru selepas training.

Sistem Pendidikan modern di negara Mesir meliputi: (Kedutaan Besar Republik Indonesia, 1983:75)

Sekolah Dasar (Ibtida'i). selama 5 tahun

Sekolah Menengah Pertama (I'dadi). Selama 3 tahun

Sekolah Menengah Atas (Tsanawiyah 'Ammah). Selama 3 tahun

Pendidikan Tinggi. Selama 4-6 tahun.

a. Sistem Sekolah Sekuler (Umum)

Jenjang pertama yang dikenal dengan "Sekolah Dasar" mulai dari "Grade 1" samapai "Grade5", dan jenjang kedua, yang dikenal dengan "Sekolah Persiapan", mulai dari "Grade 6" sampai "Grade" 8. Sekolah persiapan ini baru menjadi pendidikan wajib dalam tahun 1984. Pada sekolah umum tahun pertama (Grade 9) adalah kelas pertama pada Grade 10 murid harus memilih antara bidang sains dan non sains (IPA vs Non IPA) untuk Grade 10 dan 11.

b. Sistem Sekolah Al-Azhar

Sistem sekolah ini hampir sama dengan sistem sekolah sekuler ada tingkatan sekolah dasar. Perbedaannya ialah 
bahwa pendidikan agama Islam lebih mendapat tekanan. Dalam kurikulumya terdapat perbedaan, murid boleh memilih apakah ingin masuk ke sekolah umum dua tahun lagi atau masuk ke sekolah agama selama dua tahun.

Pada tingkatan universitas, misalnya terdapat fakultasfakultas umum konvensional seperti kodokteran, Teknik, Farmasi, Pertanian dan lain-lain, juga memiliki fakultas Darul 'Ulum yang menyelenggarakan studi Islam. (Kedutaan Besar Republik Indonesia, 1983:44)

c. Pendidikan Nonformal

Pendidikan Nonformal didefinisikan sebagai serangkaian kegiatan pendidikan terencana diluar sistem pendidikan ini dimaksudkan untuk melayani kebutuhan pendidikan bagi kelompok-kelompok orang tertentu apakah itu anak-anak, generasi muda, atau orang dewasa; apakah mereka laki-laki atau perempuan, petani, pedagang, atau pengrajin; apakah mereka dari keluarga orang kaya atau keluarga miskin.

Sistem pendidikan Mesir, baik sekolah negeri maupun AlAzhar, dan pendidikan swasta lainnya, memang mewajibkan pelajar Muslim untuk menghafal Al-Quran. Selain itu, pengajian di mesjid-mesjid bagi jamaah, khususnya anak-anak sekolah juga berperan penting untuk mendorong warga menghafal Al-Quran, kata Menteri Zakzouk, yang juga mantan dekan fakultas teologi Universitas Al-Azhar tersebut. (Abdul Sani, 1998: 54)

Sistem pendidikan di Mesir, sejak taman kanak-kanak sudah diwajibkan menghafal Al-Quran. Di Universitas Al-Azhar, misalnya, bagi mahasiswa Mesir program S-1 diwajibkan menghafal 15 juz (setengah) Al-Quran, program S-2 diwajibkan menghafal seluruh Al-Quran. Adapun program S-3, tinggal diuji hafalan sebelumnya.

Kewajiban hafal Al-Quran ini tidak berlaku bagi mahasiswa asing non-Arab, di mana program S-1 diringankan, yaitu hanya diwajibkan hafal delapan juz Al-Quran, dan program S-2 sebanyak 15 juz Al-Quran, sementara program S-3 baru diwajibkan hafal seluruh Al-Quran.

Sementara itu, Pemerintah Mesir dilaporkan setiap tahun mengalokasikan dana khusus sebesar 25 juta dolar AS (1,2 miliar pound Mesir) untuk penghargaan bagi penghafal Al-Quran. Penghargaan itu diberikan setiap peringatan hari-hari Besar Islam 
bagi pemenang hifzul (penghafal) Al-Quran, berupa uang tunai maupun dalam bentuk beasiswa dan tunjangan hidup. Sudah menjadi tradisi di negeri Seribu Menara itu, perlombaan hafal Al-Quran di setiap hari-hari besar Islam dilakukan secara serentak dari tingkat pusat hingga ke daerah-daerah.

\section{Kurikulum dan Metodologi Pengajaran di Mesir}

Kurikulum di ambil berdasarkan kondisi yang ada yang masuk di dalamnya al-Quran dan pengajaran keagamaan (ada mata pelajaran alternatif bagi murid non muslim), bahas Arab, pendidikan Kewarganegaraan, Matematika, Geometry terapan, Sejarah Geografi, Ilmu Pengetahuan Alam Dan Ilmu Dasar. Kesehatan, menggambar olah raga, kerajinan tangan untuk lakilaki dan ilmu tata boga bagi anak perempuan, kesenian. Kurikulumnya menekanankan pendidikan keagamaan bahasa Arab dan Sejarah serta masuk di dalamnya sain dan bahasa Inggris sebagai bahasa asing. SMP yang untuk 3 tahun di telah dibagi setelah yang pertama ke dalam bagaian literasi dan saintifik dengan ketentun untuk 2 bahasa asing biasanya ingris dan prancis. Walaupun dalam teorinya murid dalam hal literasi dapat memilih bahasa jerman italia spanyol atau rusia. Dari tipe sekolah menengah inilah universitas telah merekrut mahasiswa.(Sukino 2016:33)

Metode pengajaran. Di Mesir, kurikulum adalah hasil pekerjaan tim. Tim kurikulum ini terdiri dari konsultan, supervisior, para ahli, para profesor pendidikan, dan guruguru yang berpengalaman. Biasanya ada se buah panitia untuk setiap mata pelajaran atau kelompok pelajaran, dan ketua- ketua panitia diundang rapat sehingga segala keputusan dapat dikoordinasikan. Kurikulum yang sudah dihasilkan oleh panitia diserahkan kepada Dewan Pendidikan Pra Universitas yang secara resmi mengesahkannya untuk dimplementasikan. Berdasarkan peraturan, kurikulum dapat dirubah dan disesuai kan untuk mengakomodasikan kondisi setempat atau hal-hal khusus. Pusat Penelitian Pendidikan Nasional bertanggung jawab mengumpulkan informasi mengenai materi pengajaran berdasarkan kurikulum dan mengenai implementasinya di lapangan. Hasil penelitian itu disalurkan ke Dewan 
Kesekretariatan, dan apabila diperlukan perubahan, sebuah panitia dibentuk dan diserahi tugas untuk mempelajarinya dan merumuskan perubahan-perubahan itu. Ada berbagai cara untuk terjaminnya relevansi dan diseminasi program baru. Sejumlah besar supervisior, konsultan dari semua level bertemu secara reguler dengan guru-guru guna memberikan bimbingan dan untuk mengumpulkan informasi. Ada berbagai pusat latihan, sekolah percobaan, dan sekolah percontohan, yang bertujuan untuk pembaharuan kurikulum serta perbaikan metode mengajar.(Yunitasari 2017:126)

Biasanya ada sebuah panitia untuk setiap mata pelajaran atau kelompok pelajaran, dan ketua-ketua panitia ini diundang rapat sehingga segala keputusan dapat di koordinasikan. Kurikulum yang sudah dihasilkan oleh panitia diserahkan kepada Dewan Pendidikan Para universtias yang secara resmi mengesahkan untuk diimplementasikan. Berdasarkan peraturan, kurikulum dapat diubah dan disesuaikan untuk mengakomodasikan kondisi setempat atau hal-hal khusus.

\section{Pendidikan Islam Di India}

\section{Masuknya Islam ke India}

Terdapat hubungan fungsional antara masuknya Islam ke suatu wilayah dengan pendidikan. hubungan ini dapat dilihat dari dua sisi sebagai berikut: (Abudin Nata, 2014: 223)

Pertama, pada satu sisi pendidikan menjadi sarana atau media bagi terjadinya proses transmisi (perembesa), sosialisasi, dan transformasi ajaran islam ke dalam kehidupan masyarkat. Tumbuhnya tempat-tempat peribadatan islam, seperti masjid, tempattempat pengajian dan pengajaran islam seperti majelis taklim dan pesantren, upacara hari-hari besar keislaman, bentuk dan model pakaian, tempat tinggal, makanan dan minuman yang dikonsumsi, bahkan kesenian, kebudayaan, dan peradaban islam tidak dapat dilepaskan dari peran pendidikan Islam yang mentransimisikan, mensosialisasikan, dan membudayakannya.

Kedua, pada sisi lain, ajaran dan nilai-nilai ajaran islam memberi spirit, jiwa, sifat, corak, roh, dan karakter bagi pendidik itu sendiri. Ajaran islam tentang kewajiban menuntut ilmu dari buayan 
hingga ke liang lahat, kewajiban mengajarkan ilmu, berkelana berbagai tempat dan negara yang jauh untuk menuntut ilmu (rihlah ilmiah), kewajiban membaca, menulis, dan meneliti, kewajiban berpikir tentang segala sesuatu yang diciptakan Allah SWT, pendidikan yang sesuai dengan fitrah manusia dan kebutuhan masyarakat, bersikap terbuka dalam menerima pemikiran dari manapun, bersikaplah kritis dan ilmiah, yakni melakukan proses tabayun terhadap setiap informasi yang datang, dan memandang mencari ilmu sebagai ibadah merupakan nilai-nilai ajaran islam yang selain menjadi dasar bagi pengembangan ajaran islam tersebut, juga menjadi ciri dan karakter pendidikan barat yang bertumpu pada paham positivisme, empirisme, dan antroposentrisme. Adapun nilainilai ajaran islam bertumpu pada perpaduan yang seimbang antara hubungan manusia dengan tuhan (teosentris) hubungan manusia dengan manusia (antroposentris), hubungan manusia dengan alam (cosmo sentris).

Setelah berakhirnya ke Sultanan Delhi di India, Masuklah Dinasti Mughol ke India, Dinasti Mughol merupakan kerajaan Islam di India. Kontribusi Dinasti Mughol dibidang arsitektur dan ilmu pengetahuan. Pada masa pemerintahan Islam di India, muncul hasil karya-karya yang indah. Para penguasannya banyak menyukai keindahan. Bangunan seperti masjid jama di Delhi, makam Jahangir dan taman shalimar di Lahore serta Taj Mahal di Agra, bangunan yang indah dan megah yang hingga saat ini masih dikunjungi wisatawan dari berbagai negara. Demikian juga dibidang seni, saat itu sejumlah karya para penyair seperti Urfi, Naziri, dan Zanuri, menduduki posisi-posisi tinggi dalam sejarah puisi Persia, selain dibidang sastra bidang seni lukis juga berkembang. (Imam fu'adi, 2012: 259-257)

\section{Pendidikan Islam di India}

Pembaharuan di India dilatarbelakangi oleh kondisi yang terjadi terhadap umat Islam India. Kemajuan yang dicapai pada masa dinasti Mughal merupakan sumbangan yang berarti dalam mensyiarkan dan membangun peradaban Islam di India. (Dudung Abdurrahman, 2002: 187). Sejak abad ke 18, kekuasaan kerajaan Islam Mughal mulai melemah. Kekuatan Inggris semakin menguat, begitu juga dominasi Hindu semakin mendesak umat Islam. Perlawanan-perlawanan kaum mujahidin yang di pelopor oleh Sayyid Ahmad Syahid mengalami 
kegagalan. Situasi umat Islam di India semakin terpuruk ketika terjadinya peristiwa Mutiny ( Pemberontakan) ditahun 1857. Peristiwa ini memukul umat Islam, Sayyid Ahmad Khan berupa menetralisasi keadaan tersebut.

Dalam peristiwa itu, Sayyid Ahmad Khan banyak menyelamatkan dan membantu Inggris dari tindakan kekerasan dan pembunuhan. Sayyid Ahmad Khan dapat mengubah pandangan Inggris terhadap umat Islam berkenaan dengan Mutiny ( Pemberontakan). Menurut beliau ketertinggalan umat Islam India adalah disebabkan karena ketertinggalan dalam bidang Ilmu Pengetahuan, ketertinggalan itu karena akal tidak berfungsi dengan benar. Jalan untuk mencapai kemajuan itu adalah lewat pendidikan. Mulailah Sayyid Ahmad Khan mempelopori pembangunan di bidang Pendidikan. ( Haidar \& Nurgaya, 2013: 161-162) Dinasti Mughal juga banyak memberikan sumbangan di bidang ilmu pengetahuan. Sejak berdiri, banyak ilmuwan yang datang ke India untuk menuntut ilmu pengetahuan, bahkan Istana Mughal pun menjadi pusat kegiatan kebudayaan. Hal ini karena adanya dukungan dari penguasa dan bangsawan serta ulama. Aurangzeb misalnya, memberikan sejumlah besar uang dan tanah untuk membangun pusat pendidikan di Lucknow.

Pada tiap-tiap masjid memiliki lembaga tingkat dasar yang dikelola oleh seoarang guru. Pada masa Shah Jahan didirikan sebuah perguruan tinggi di Delhi. Jumlah ini semakin bertambah ketika pemerintahan dipegang oleh Aurangzeb. Di bidang ilmu agama berhasil dimodifikasikan hukum islam yang dikenal dengan sebutan Fatawa-I-Alamgiri (Dudung Abdurrahman, 2002: 187-189). Sejumlah madrasah didirikan dan para gurunya diberi gaji oleh pemerintah. (Ira M Lapidus, 2000:686)

Penguasa Islam yang pertama di India adalah Muhammad Ibnu

Qasim, ia sangat pandai memutar roda pemerintahan dan sesuai dengan instruksi dari Amir Umayyah yaitu Hajjaj Bin Yusuf di Propinsi bagian Timur. Muhammad Ibnu Qasim menjadi panutan masyarakat India, karena ia memberikan kebebasan kepada rakyat untuk memeluk agama, boleh masuk agama Islam dan boleh tetap menganut agama nenek moyang mereka. Mereka yang beragama Islam diharuskan membayar zakat dan bagi yang bukan agama Islam agar dapat membayar jizyah. Setelah Muhammad Ibnu Qasim wafat, ia digantikan oleh 
Muhammad Ghazni pada tahun $1012 \mathrm{M}$, yang berkedudukan di kota Delhi. Dialah yang membangun kota Delhi dan pembangunan kebudayaan. Penguasa Islam selanjutnya yang terkenal di India adalah Kaisar Mongol (tahun 1526).(Akmal 2015:2) India baru mencapai masa kejayaannya pada masa Kaisar Akbar Agung, Syeh Jehan dan Aurangzeb. Pada masa pemerintahan mereka rakyat merasa terlindungi dalam aktivitas sehari-hari dan kebebasan beragama. Bahkan Akbar Agung menciptakan agama baru yang campuran dari beberapa agama yang terdapat di India. Agama ini di kenal dengan Dinillah. "Bidang lain yang mengalami kemajuan adalah bidang ilmu pengetahuan, ekonomi, seni, sastra dan kebudayaan. Keindahan pada seni lukis dan seni ukir terlihat pada bangunan Mesjid Quwwatul Islam, Qutub Minar, Qilal Qirwan, gedung perkuliahan, taman Shalimar dan Makan Taj Mahal. Tiada tara akan keindahannya dan pilih tanding dalam sejarah dunia. Amir Hasan dalam (Akmal 2015:2) Tanpa kedatangan agama Islam ke India mungkin tidak akan pernah ada rekaman mengenai masa lalu India. Bahasa sehari-hari di India banyak coraknya, ada bahasa India, Sanskerta, dan Parsia. Dengan pengaruh bangsa Arab terciptalah bahasa lain India yaitu bahasa Urdu.

Pengaruh yang diterapkan oleh Inggris tidak selalu diterima oleh rakyat dan pemuka masyarakat India. Misalnya dibidang agama menimbulkan kebencian masyarakat India terhadap Ingris karena terlalu jauh mencampuri urusan keagamaan. Pada tahun 1857 terjadi pemberontakan orang-orang Hindu bersama umat Islam melawan Inggris, pemberontakan ini dikenal dengan pemberontak Sepoy. Abu a'la maududi dalam (Akmal 2015:4)

Setelah terjadinya pemberontak Sepoy itu, Sayyid Ahmad Khan memberikan pandangan terhadap umat Islam bahwa keselamatan umat Islam tergantung kepada kerjasama dengan orang Inggris. Perselisihan antara agama di dalam ajaran agama Islam dilarang. Kalau kita kalah dalam pertempuran, itu adalah kehendak dari Allah. Maka semestilah kita patuh dan ta'at pada pemerintahan. Al-Quran menjelaskan dalam surat An-Nisa': 59. Berbunyi sebagai berikut:

"Wahai orang-orang yang beriman! Taatilah Allah dan taatilah Rasul (Muhammad), dan ulil amri (pemegang kekuasaan) di antara kamu. Kemudian, jika kamu berbeda pendapat tentang sesuatu, maka kembalikanlah kepada Allah (Al-Qur'an) dan Rasul (Sunnahnya), 
jika kamu beriman kepada Allah dan hari kemudian. Yang demikian itu, lebih utama (bagimu) dan lebih baik akibatnya." (Q.S.AnNisa:59)

Hubungan baik dengan imperialis Inggris akan membantu dalam berkomunikasi dan juga mengangkat derajat umat Islam di tengah pemerintahan Inggris. Langkah selanjutnya yang dilakukan oleh Sayyid Ahmad Khan adalah mengadakan dialog dengan masyarakat di India, khusus masyarakat Hindu dan Islam. Hasil dialog itu melahirkan suatu partai politik yaitu The Indian National Congres (Muktamar Nasional India) yang berdiri tahun 1885. Organisasi tidak bertahan lama kerana memakai bahasa Urdu dan Hindi sebagai bahasa partai.

Sayyid Ahmad Khan bukan orang yang mudah berputus asa, untuk memajukan umat islam satu-satunya jalan adalah melalui pendidikan. Melalui pendidikan akan lahirlah para intelektual Islam. Ilmu pengetahuan dapat memaju kemajuan dan melahirkan kebudayaan modern. Oleh karena itu, ia banyak berkecimpung di dunia pendidikan. Dengan semangat yang tinggi ia bersama dengan kawannya mendirikan sekolah Muhammaden Anglo Oriental College (M. A. O. C.) di Aligarh pada 1 Januari 1878.(Akmal 2015:5)

Sayyid Ahmad Khan lebih condong memiliki pemikiran modern. Dengan berfikiran secara modern akan mampu membawa umat Islam ke arah yang lebih cerah. Untuk itu India ingin pembaharuan yaitu dalam pengelolaan pendidikan dan pengajaran memakai kurikulum pendidikan dan menggabungkan pelajaran ilmu pengetahuan modern dengan pelajaran agama. Dengan cara itu tidak akan terjadinya pemisahan antara pelajaran agama dengan pelajaran umum. Sebelumnya umat Islam India hanya mempelajari agama saja dan mengabaikan pengetahuan umum. Pembaharuan yang dilakukan Sayyid Ahmad Khan terutama pendidikan M.A.O.C. banyak membantu pemerintah Inggris yang menyiapkan tenaga kerja seperti: hakim, pegawai-pegawai sipil dan pajabat-pejabat penting lainnya. Namun disayangkan sekolah ini tidak ada mengahasilkan sarjana ilmu ukur, mekanika, kimia, ilmu perindustrian, dan ilmu yang lain yang bermanfaat untuk umat Islam di India. Kemudian pendidikan M.A.O.C. berkembang menjadi Universitas Islam Aligarh pada tahun 1920. 
Universitas Islam Aligarh merupakan salah satu pusat budaya Islam terbesar di Asia.(Akmal 2015:16)

Maka, dengan demikian pemikiran sayyid Ahmad Khan sangat bagus dan modern dalam memajukan masyarakat india di bidang pendidikan, membantu generasi muda untuk mengerti pentingnya ilmu pengetahuan. Dengan ilmu dapat meingkatkan derajat manusia. Sebagaimana dalam firman Allah. SWT dalam Qur'an Surah AlMujadilah ayat ke 11, yang artinya :"Wahai orang-orang yang beriman! Apabila dikatakan kepadamu, "Berilah kelapangan di dalam majelis-majelis," maka lapangkanlah, niscaya Allah akan member kelapangan untukmu. Dan apabila dikatakan," Berdirilah kamu," maka berdirilah, niscaya Allah akan mengangkat (derajat) orang-orang yang beriman di antaramu dan orang-orang yang diberi ilmu beberapa derajat. Dan Allah maha teliti apa yang kamu kerjakan.”(QS. Al-Mujadillah (58):11)

\section{A. Madrasah di India}

\section{1) Universitas Muslim Aligarh di India}

Sejarah berdirinya.

Setelah Sayyid Ahmad Khan dapat menetralisir peristiwa Mutiny (1857), maka beliau berkonsentrasi dalam bidang pendidikan, karena menurut beliau pendidikanlah yang dapat mengangkat kembali derajat kaum Muslimin India serta mengatasi berbagai masalah. Seterusnya di tahun 1920 berdirilah Universitas Alighar (Alighar Muslim University). Universitas ini telah melahirkan banyak alumni yang mempunyai peranan yang besar di India dan Pakistan. Gerakan Alighar ini digagas oleh Sayyid Ahmad Khan masyarakt Muslim India di abad ke 19 berada dalam situasi yang memprihatinkan. Setelah runtuh kekuatan kerajaan Islam Mughal dan Inggris mendominasi Kekuasaan di India. ( Haidar \& Nurgaya, 2013: 168)

Dasar dan Tujuan Universitas Muslim Aligarh di India

Pada tahun 1875, Sayyid Ahmad Khan mendirikan Kolese Anglo Oriental Mohammadan yang kemudian menjadi Unversitas Muslim Islam Aligarh, dengan model Oxford dan Cambrige, dan bertujuan melahirkan kaum berpendidikan 
Inggris. Sayyid Ahmad Khan mendapati bahwa warisan intelektualnya adalah dari para pembaharu Wali Allah. Namun, dia bertujuan menunjukan keselarasan fundamental antara wahyu Al-qur'an dan sains modern, dengan menyingkirkan dari Islam unsur-unsur yang bergantung pada ruang dan waktu tertentu serta hanya mempertahankan yang esensial. Dia menggunakan ijtihad untuk menggantikan penafsiran historis.

Kurikulum Universitas Muslim Aligarh di India

Kemajuan Gerakan Aligarh disebabkan adanya mata pelajaran umum, seperti ilmu alam, filsafat, dan sebagainya.

\section{2) Madrasah Dar Al-'Ulum di India}

a. Sejarah berdirinya Darul Ulum Deoband

Pembaruan pendidikan di India dapat juga dilihat dari lahir dan berkembangnya madrasah Deoband yang ditingkatkan statusnya menjadi Perguruan Tinggi yang bernama Darul Ulum Deoband. Sekolah inilah yang kemudian melahirkan ulama-ulama besar India dan melalui ulama-ulama ini Deoband mempunyai pengaruh besar bagi masyarakat India. gambaran dan kondisi masyarakat Muslim di India pada abad ke sembilan belas. Suasana itu semakin memprihatinkan lagi ketika terjadi Mutiny (pemberontakan), dan terjadi pula konflik Horizontal dikalangan masyarakat India. Pada suasana yang seperti itulah muncul seorang Tokoh pembaru Muslim India Sayyid Ahmad Khan. Beliau merenungkan apa yang terjadi di India itu tiada lain karena kebodohan, oleh karena itu dia bertekad untuk mendidik orang-orang yang memerintah dan di perintah. Untuk itu ia menulis buku Causes Of The Indian Refolt. Pada tahun 1866 ia mendirikan British Indian Association. Ia juga menerbitkan majalah The Loyal Mehammadans of India untuk menghapus citra kejadian pemberontakan adalah pemberontakan kaum Muslim, dan umat Islam di tindas karena itu. ( Haidar \& Nurgaya, 2013: 168-170)

b. Dasar dan Tujuan Pendidikan Madrasah Dar Al-'Ulum di India 
Doeban bertujuan memberikan pendidikan terorganisasi secara birokratis dalam ilmu tradisional ulama. Yang diutamakan ialah pemurnian tauhid yang dianut umat Islam India dari paham-paham salah yang dibawa tarekat dan dari keyakinan animisme lama. Selanjutnya juga pemurnian praktek keagamaan mereka dari segala macam bidah. Yang ingin diwujudkan doeband kembali ialah Islam murni sebagai terdapat di zaman Nabi, Sahabat, tabiin, dan zaman sesudahnya. Doeband dengan demikian kuat berpegang pada tradisi zaman klasik. Mazhab yang dianut Doeband mazhab Hanafi.

c. Kurikulum Pendidikan Madrasah Dar Al-'Ulum di India.

Para siswa mengikuti pendidikan selama enam tahun, mengikuti silabus, menempuh ujian formal, dan ikut pertemuan. Sekolah ini terutama terkenal karena karyannya dalam Hadis, dan pada abad ini membangun jaringan sekolah yang masih terus tumbuh hingga sekarang.

\section{3) Sekolah Muhammedan Anglo Oriental College (MAOC) di India}

a. Sejarah Berdirinya

Pada tahun 1878, Sayyid Ahmad Khan mendirikan Muhammaden Anglo Oriental (M.A.O.C) di Alighar yang merupakan karyanya yang bersejarah dan berpengaruh dalam cita-citanya untuk memajukan umat Islam India. Tahun 1878 ia mendirikan Muhammaden Anglo Oriental College (MAOC) sekolah ini dibentuk sesuai dengan model sekolah di Inggris dan bahasa yang dipakai adalah bahasa Inggris. Ilmu pengetahuan Modern merupakan sebagian besar dari mata pelajaran yang diberikan. Pendidikan agama tidak diabaikan. Di MAOC pendidikan agama Islam dan ketaatan siswa menjalankan agama diperhatikan dan dipentingkan. Sekolah ini terbuka bukan saja bagi orang Islam, tetapi juga bagi seorang Hindu, Parsi, dan Kristen. ( Haidar \& Nurgaya, 2013: 168-172)

b. Dasar dan Tujuan Sekolah Muhammedan Anglo Oriental College (MAOC) di India

Menurut penulis I.H. Qureshi, sekolah-sekolah itu mempunyai peranan penting dalam kebangkitan umat Islam 
India, dan sekiranya tidak karena sekolah itu, umat India dan Pakistan sekarang akan lebih jauh ketinggalan dari umat-umat lain. Perhatian Sayyid Ahmad Khan terhadap umat Islam memang besar, tetapi pengaruhnya tidak terbatas dalam pendidikan saja. Melalui buku karangannya dan tulisannya di Tahzib al-Akhlaq ide-ide pembaharuan yang dicetuskannya menarik perhatian golongan terpelajar Islam India. Penafsiran-penafsiran baru yang diberikannya terhadap ajaran-ajaran Islam lebih dapat diterima golongan pelajar ini dari pada tafsiran-tafsiran lama.

c. Kurikulum Sekolah Muhammedan Anglo Oriental College (MAOC) di India

MAOC dibentuk sesuai dengan model sekolah di Inggris dan bahasa yang dipakai di dalamnya ialah bahasa Inggris. Sedang guru dan stafnya banyak terdiri atas orang Inggris. Ilmu pengetahuan modern merupakan sebagian besar dari mata pelajaran yang diberikan. Pendidikan agama tidak di abaikan. Dalam hubungan ini baik disebut bahwa di sekolahsekolah inggris yang diasuh pemerintah, agama tidak di ajarkan. Di MAOC pendidikan agama Islam dan ketaatan siswa menjalankan ajaran agama diperhatikan dan di pentingkan. Sekolah itu terbuka bukan hanya bagi orang Islam, tetapi juga bagi orang Hindu, Parisi, dan Kristen.

\section{Sistem Pendidikan di Pakistan}

\section{A. Sejarah Singkat Tentang Pakistan}

Pakistan muncul sebagai negara Republik Islam pada tanggal 14 Agustus 1947 Negara Ini memiliki luas sekitar 796,095 Sq Kilometer. Pakistan terdiri dari empat provinsi: Punjab, North West Frontier Provinsi, Balochistan dan Sindh dan beberapa unit penyatuan yang meliputi Islamabad Modal Wilayah (ICT), Wilayah Kesukuan Federal (FATA) dan Wilayah Utara (Fana). Islamabad adalah ibukota Pakistan, yang terletak di bagian utara negara di bagian bawah dari Margalla Hills dekat Rawalpindi, adalah kota yang direncanakan dengan baik, yang dibangun di awal 1960-an. Bahasa nasional adalah Urdu. Bahasa Inggris digunakan secara luas untuk hukum dan lainnya resmi bisnis, komersial di negeri ini. Sekitar 97 persen dari orang Muslim. 
Mayoritas orang Pakistan (97\%) adalah Muslim. Minoritas non muslim termasuk orang Kristen, Hindu dan Persi. Di antara muslim $10 \%$ sampai $15 \%$ adalah syiah Istna 'Asya'ariyah (Dua belas Imam). Minoritas sekte Syi'ah termasuk Isma'illiyah, kebanyakan terdapat di Kara- chi, wilayah barat laut Gilgit, dan Bohoras, sedangkan markas spritualnya terletak di Bombay, India. Mayoritas besar kaum Muslimi Sunni. Pakistan menganut Mazhab Hanafi meskipun minoritas kecil pengikut Mazhab Hambali. Ajid Thohir dalam (Surawardi 2012:41) Bahasa Urdu adalah sebagai bahasa umum masyarakat Pakistan dan merupakan bahasa baru yang lahir akibat akumulasi etnik dan percampuran berbagai pengaruh budaya dan bahasa, terutama Persia, Turki, India dan Arab sejak abad ke-13 M di sekitar wilayah-wilayah Afghanistan, Pakis- tan, Banglades dan India sekarang. Kesultanan Mughal, tampaknya salah satu hegemoni politik yang paling bertanggung jawab pada kurun abad ke-16 $\mathrm{M}$ akan kepentingan bahasa Urdu ini, sebagai manifestasi dari kekuatan sosial-budaya di India yang hendak mengidentifikasikan diri dan mencoba membedakan dirinya dan kekuatan Shafawiyah di persia dan Utsmaniyah.

\section{B. Kebijakan dan Tujuan Sistem Pendidikan di Pakistan}

Sejak kemerdekaan, upaya telah dilakukan untuk mengaitkan sistem pendidikan dengan kebutuhan Semua Konferensi Pendidikan diselenggarakan pada tahun 1947 sesuai arahan pendiri Pakistan Quaid-e-Azam Muhammad Ali Jinnah. Dia menyediakan pedoman dasar untuk pengembangan masa depan pendidikan dengan menekankan interalia, bahwa sistem pendidikan harus sesuai dengan jenius rakyat kita, konsonan dengan budaya, sejarah kita dan menanamkan tertinggi rasa kehormatan, integritas, tanggung jawab, dan pelayanan tanpa pamrih bagi bangsa dan negara.

Sistem pendidikan di Pakistan umumnya dibagi menjadi lima tingkatan: primary /primer (kelas satu sampai lima), middle/tengah (kelas enam sampai delapan), high/menengah (sembilan dan sepuluh, yang mengarah ke Sekolah Menengah, Certificate atau SSC), intermediate/tinggi (kelas sebelas dan dua belas, yang mengarah ke Higher Secondary (Sekolah) Sertifikat atau HSC), program dan universitas terkemuka sarjana dan gelar 
sarjana.(Surawardi 2012:43) Kurikulum biasanya mencakup kombinasi dari delapan program termasuk pilihan (seperti Biologi, Kimia, dan Fisika Komputasi) serta mata kuliah wajib (seperti Matematika, Bahasa Inggris, Urdu, Islamiat dan Studi Pakistan).

Dalam sistem pendidikan formal, ada beberapa tahap, yang diilustrasikan dalam diagram seperti yang dijelaskan secara singkat di bawah ini:

1. Pendidikan Formal

a. Pra Sekolah Dasar: Pra pendidikan dasar adalah fungsional dan dikelola di sekolah-sekolah melalui luar negeri. sekolah umum menyediakan-dasar pendidikan anak usia sebagai bagian dari proses sosialisasi. siswa yang menghadiri kelas pra-primer disebut Kachi. Kebijakan, 1998-2010 memberikan pengakuan ke kelas Kachi sebagai proxy untuk pendidikan anak usia dini

b. Sekolah Dasar: Tahapan ini terdiri dari lima kelas IV dan mendaftar anak anak usia 5-9 tahun. Sejak kemerdekaan, para pembuat kebijakan diucapkan untuk membuat pendidikan dasar gratis dan wajib.

c. Tengah Sekolah: sekolah menengah ini adalah tiga tahun lamanya dan terdiri dari kelas VI, VII dan VIII Kelompok umur 10-12 tahun

d. Sekolah Tinggi: Anak-anak sekolah menengah tinggal selama dua tahun di kelas IX dan X. dewan Menengah dan Pendidikan Menengah melakukan pemeriksaan. Sebuah sertifikat sekunder sekolah diberikan kepada kandidat yang berhasil.

e. Pendidikan Menengah Tinggi: Tahap sekunder lebih tinggi juga disebut " tahap "dan dianggap sebagai bagian dari pendidikan perguruan tinggi. Menengah Pendidikan Tinggi terdiri dari kelas XI ke XII. Dewan Pendidikan Menengah dan Menengah (Bise) melakukan pemeriksaan dan penghargaan Sertifikat Sekolah Menengah Tinggi Pendidikan (HSSC). Menurut 1979 Kebijakan Pendidikan, semua sekolah itu harus ke Sekolah Menengah yang lebih tinggi. Tengah bagian sekolah tinggi itu harus dikaitkan dengan sekolah dasar (menunjuk pendidikan dasar). sistem memiliki keberhasilan terbatas dan beberapa masalah yang dialami

f. Pendidikan Tinggi: Untuk mendapatkan gelar, 4 tahun pendidikan tinggi setelah 10 tahun primer dan sekolah 
menengah diperlukan. Dalam rangka menyelesaikan Tentu saja gelar kehormatan di tingkat tambahan satu tahun studi adalah diperlukan. Lebih lanjut, Tentu saja dua tahun diperlukan untuk gelar Master yang telah menyelesaikan dua tahun Sebuah gelar doktor membutuhkan biasanya 3 tahun studi setelah selesai master derajat saja. Khusus untuk jenjang perguruan tinggi, sejak pemisahan dengan India tahun 1947, Pakistan hanya memiliki 1 universitas saja, Universitas Punjab di Lahore. Mata kuliyah agama diberikan sebagai mata kuliyah dasar umum. Universitas ini mendirikan departemen Islamiyat pada tahun 1950. Setelah itu berdiri berbagai perguruan tinggi lainnya seperti Universitas Sind yang membuka fakultas sejarah dan kebudayaan Islam sejak awal tahun 1950-an.

g. Profesional dan Teknis Pendidikan: Lama pendidikan pasca sekunder bervariasi di teknis dan profesional bidang. Diploma politeknik adalah program tiga tahun. Seorang sarjana dalam kedokteran (MBBS) membutuhkan 5 tahun studi setelah tahap peralihan (12 tahun sekolah). Demikian pula,'s gelar sarjana saja baik dalam dan kedokteran hewan rekayasa dari 4 tahun lamanya setelah pemeriksaan menengah.

h. Pendidikan madrasah: Berdampingan dengan sistem pendidikan modern ada juga agama sistem pendidikan, yang menyediakan pendidikan Islam. Lembaga ini memiliki sendiri manajemen sistem tanpa campur tangan baik dari pemerintah provinsi atau federal. (Khan, 2002). Upaya telah dilakukan oleh pemerintah hadir untuk membawa madrasah dalam arus utama dalam Reformasi Sektor Pendidikan. Tujuan utama dari pengarusutamaan madrasah adalah untuk memperbesar peluang kerja bagi para lulusan mereka. Pakistan. Madrasah Dewan Pendidikan dibentuk untuk mengatur kegiatan Madaris.

Menurut UNESCO 2009 Global Education Digest, 6,3\% dari Pakistan (8,9 \% laki-laki dan 3,5\% perempuan) adalah lulusan universitas pada 2007. Pakistan berencana untuk meningkatkan angka tersebut menjadi $10 \%$ pada tahun 2015 dan selanjutnya menjadi 15 $\%$ pada tahun 2020. Ada juga banyak variasi antara kelompok usia. Kurang dari 6\% dari mereka yang berada di kelompok umur 55-64 memiliki gelar, dibandingkan dengan $8 \%$ pada kelompok umur 45 $54,11 \%$ dalam kelom- pok usia 35-44 dan $16 \%$ pada kelompok 
umur 25-34. GIK Institute dari Menara Jam Quaid -i- Azam Universitas entrance. Setelah mendapatkan HSC mereka, siswa dapat belajar di sebuah perguruan tinggi profesional untuk program gelar Bachelor seperti teknik (B.Engg/BS Engg.), B.Tech Hons / BS Engg.Tech kedokteran (MBBS), kedokteran gigi (BDS), kedokteran hewan (DVM), hukum (LLB), arsitektur (B.Arch), farmasi(Pharm-D) dan keperawatan (B.Nurs). Kursus ini membutuhkan empat atau lima tahun studi. Ada beberapa dewan dan papan yang akan menangani semua urusan pendidikan dalam kasus ini, mereka adalah PMDC, Pakistan dewan farmasi dan Pakistan dewan keperawatan. Siswa juga dapat menghadiri sebuah universitas untuk Bachelor of Arts (BA), Bachelor of Science (BSc), Bachelor of Commerce (BCom) atau Bachelor of Business Administration (BBA) program gelar. Semua ini adalah program yang dilakukan di Pakistan dan benar-benar umum. Hari-hari ini dokter farmasi juga mendapatkan banyak reputasi. Dewan farmasi Pakistan melakukan perjuangan besar untuk membuat pendidikan farmasi yang lebih baik.(Surawardi 2012:45)

Dalam hal kurikulumnya lembaga ini dipengaruhi oleh Universitas al Azhar, Mesir. Dalam kajian tradisional-keagamaannya dimasukkan ilmu ekonomi, sejarah, geografi, statistik, dan filsafat. Kemuidan Pada tahun 1980 didirikan Universitas Islam Internasional di Islamabad yang berupaya menyatukan sistem pendidikan keagamaan dan umum. Baru-baru ini pemerintah Pakistan mendirikan sebuah akademi yang bergerak di bidang pelatihan dan sekolah menengah atas, yaitu JPSC (jinnah public school and college). Di pakistan, dapat dijumpai berbagai gerakan keagamaan yang mampu menciptakan komunitas muslim yang sesuai dengan karakternya masing-masing dengan berbagai bentuk lembaga pendidikannya. Diperkirakan lebih dari 2000 madrasah tingkat menengah dan tingkat tinggi dengan jumlah murid sekitar 316.000 orang ada di negara Pakistan.

Madrasah memainkan perananan penting karena mampu melestarikan nilai ortodoks Islam, melatih banyak generasi ulama dan fungsionaris Islam. Madrasah di Pakistan mengajarkan kurikulum yang disebut dar-i-nizhami, yaitu sebuah mata pelajaran standar bagi semua madrasah sunni di India, Pakistan, dan Bangladesh. Dalam kurikulum tersebut terdapat 20 mata pelajaran yang secara luas terbagi atas ilmu-ilmu yang diwahyukan dan ilmu rasional. 
Selain Madrasah, Masjid juga merupakan bentuk lembaga pendidikan Islam di Pakistan. Jumlah masjid jauh lebih banyak dari total madrasah. Tidak seperti kebanyakan negara Islam di timur tengah, jaringan masjid dan madrasah di Pakistan beroperasi di luar kendali negara serta memliki otonomi yang besar. Di banyak kota yang tidak mempunyai balai rakyat, selain sebagai tempat ibadah, masjid juga berfungsi sebagai forum diskusi masalah umum. (Binti Maunah, 2011: 125-150).

\section{Simpulan}

Dari ketiga model sistem pendidikan Negara tersebut di atas kita dapat mengambil kesimpulan bahwa suatu Negara berbeda pula pola sistem pendidikannya, ini bisa jadi karena dipengaruhi oleh sosiologi masyarakat, sejarah berdirinya suatu Negara, juga kebutuhan suatu Negara terhadap generasi penerus bangsanya yang sesuai dengan tuntutan jaman dan situasi Negara dan dunia yang semakin mengglobal. ketiga model pendidikan di negara mesir, india, dan pakistan tersebut kita dapat mengambil pelajaran bahwa pendidikan seharusnya dilaksanakan oleh pemerintah dan swasta, dengan sasaran pendidikan yang terjagkau bahkan gratis serta bermutu karena diselengarakan oleh pemerintah dengan dana pemerintah yang diambil dari APBN dan APBD yang bertujuan menciptakan generasi bangsa yang unggul dan berkualitas yang mampu bersaing dikancah lokal maupun global tanpa meninggalkan karakter suatu bangsa tersebut. Untuk mencapai kualitas pendidikan yang berkualitas dan unggul perlu adanya kerjasama yang baik antar stake holder pendidikan untuk menciptakan keadaan pendidikan yang kondusif dan nyaman. Tentunya untuk mencapai keadaan pendidikan yang kondusif dan nyaman dibutuhkan sarana pendidikan yang memadai, baik dari pendidik yang berkualitas dan sarana prasarana yang mendukung proses pendidikan yang memadai. 


\section{DAFTAR PUSTAKA}

Abdurrahman, Dudung. 2002. Sejarah Peradaban Islam dari Klasik Hingga Modern, Lesfi: Yogyakarta.

Akmal. 2015. "Sayyid Ahmad Khan Reformis Pendidikan Islam Di India." Potensia 14(1):1-18.

Daulay, Haidar Putra., \& Nurgaya Pasa. 2013. Pendidikan Islam Dalam Lintasan Sejarah, Kencana Prenada Media Group: Jakarta.

Fu'adi, Imam. 2012. Sejarah Peradaban Islam, Teras: Yogyakarta.

Kedutaan Besar Republik Indonesia. 1983. Pendidikan Islam di Indonesia dan Mesir, Bidang pendidikan dan kebudayaan: Cairo.

M Lapidus, Ira. 2000. Sejarah Sosial Umat Islam, PT.Raja Grafindo Grafika: Jakarta.

Maunah, Binti. 2011. Perbandingan Pendidikan Islam,Teras: Jakarta.

Murtadlo, Muhammad. 2018. "Hubungan Mesir-Indonesia Dalam Modernisasi Pendidikan Islam." Al-Qalam 24 Nomor 2(Desember):297-306.

Nasution, Harun. 1975. Pembaruan dalam Islam Sejarah Pemikiran dan Gerakan,Balan Bintang: Jakarta.

Nata, Abudin. 2014. Sejarah Pendidikan Islam, Kencana: Jakarta.

Ramayulis. 2012. Sejarah Pendidikan Islam, Kalam Mulia : Jakarta.

Sanaky, Hujair AH. 1997. "Pembaharuan Pendidikan Islam.”

Sani, Abdul. 1998. Lintasan Sejarah Pemikiran Perkembangan Modern Dalam Islam, PT Raja Grafindo Persada, Jakarta. 
112 Yesi Arikarani, Pendidikan Islam di Mesir, India, .....

Sukino, Arief. 2016. "Dinamika Pendidikan Islam Di Mesir Dan Implikasinya Terhadap Transformasi Keilmuan Ulama Nusantara." Ilmiah Pendidikan 10(1):28-39.

Surawardi. 2012. "Pendidikan Islam Di Pakistan." Management of Education 1(1):41-53.

Yunitasari, Dukha. 2017. "Memetik Pelajaran Dari Sistem Pendidikan Mesir Untuk Peningkatan Pendidikan Indonesia." 12(2):102-28. 